\title{
Main Circuit Parameters Design of DC Operating Power Supply based on Electric System
}

\author{
Bao Wen Sun andYunxi Wu \\ Depart. of Mechanical and electrical Engineering, Guangdong Institute of Science \\ and Technology, Zhuhai, Guangdong, P.R. China 519090
}

\begin{abstract}
The phase-shifted full bridge zero voltage soft switch (ZVS) topology of $2.2 \mathrm{KW}$ electric operation power supply is analyzed in brief. Then, parameters of main circuit are designed and selected. At the same time, the high frequency transformer and the oscillatory inductor are manufactured. According to the actual characteristics of electric power supply, the power MOSFET and the second rectifier-diode are chosen. By waveform analysis, temperature and power efficiency test, the experimental results confirm the reasonableness of the design.
\end{abstract}

Keywords: Electric operation, Power supply, Main circuit, ZVS

\section{Introduction}

With the development of power electronics technology, phase-shifted full-bridge soft switching control technology has been widely used in the power supply operation, which not only can reduce the switching losses, electromagnetic interference power, but also to improve the output characteristics of the circuit to improve the efficiency of the circuit, stability and reliability. In soft-switching full-bridge phase-shift Electric Power study, involving a lot of aspects, such as the parameter selection and design of the main circuit, control circuit design, anti-electromagnetic interference design and parameters of influence and so on, this paper analyzes only Electric Power main circuit parameters.

\section{Electric Power Works}

The principle of the power module block diagram shown in Figure 1. Three-phase AC input power via the input phase rectifier, filter is converted into direct current, full-bridge DC converter circuit and then converted into a high-frequency alternating current, and then by the high-frequency transformer isolation transformer, rectified by the rectifier filter is converted into a stable DC output; the main circuit switching power phase-shifted full bridge soft switching converter circuit, each one arm using two power transistors in parallel, one can ensure that the pipe will not be burned, on the other hand to prepare for the potential of the power, which the topology shown in Figure 2.

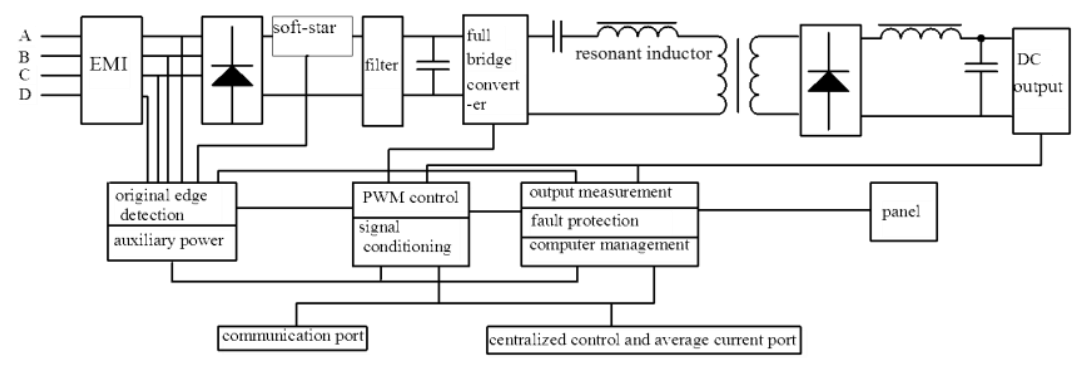

Figure 1. Block Diagram of the Electric Power Modules 


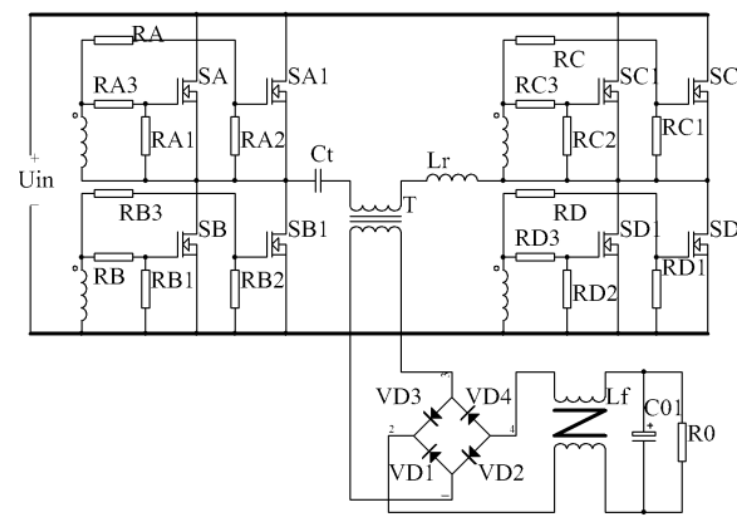

Figure 2. Full-bridge Soft-switching Converter Topologies

The converter in a transformation period, a total of 12 kinds of working conditions, four switch turns conducting achieve zero voltage turn-on and turn-off, reducing power consumption. The converter also uses the isolation capacitors to suppress the DC component, and uses the saturation inductance to reduce duty cycle loss.

\section{Design Parameters of the Main Circuit}

\subsection{The Main Circuit Design Specifications}

Three-phase AC voltage input: $380_{-20 \%}^{+15 \%}, 50_{-5}^{+5}$

Rated output DC voltage: $220 \mathrm{~V}$, Continuously adjustable in the range of $180 \mathrm{~V} \sim$ $320 \mathrm{~V}$.

Output Current: $10 \mathrm{~A}$

Maximum power output: 3200W

Output ripple factor: $\leq 0.2 \%$

Output current limit: $110 \%$ of rated output current

Operating Frequency: $34 \mathrm{KHz}$

Overall efficiency: $\geq 90 \%$

\subsection{Input Filter Capacitor Selection}

The input Three-phase 380V AC power becomes into pulsating DC voltage after the bridge rectifier. A filter capacitor $\mathrm{C}_{\text {in }}$ is added before the converter to further smooth and reduce the voltage ripple, and the noise can be greatly reduced.

RMS phase voltage: $380_{-20 \%}^{+15 \%}=304 \mathrm{~V} \sim 437 \mathrm{~V}$

In order to ensure that the filtered rectified DC voltage minimum value $V_{\text {in (min) }}$ to meet the requirements, the energy per cycle $\mathrm{C}_{\text {in }}$ provided is about:

$$
W_{\text {in }}=\frac{P_{\text {in }}}{3 \times f_{\min }}=\frac{P_{\text {out }} / \eta}{3 \times f_{\min }}=\frac{2200 / 0.85}{3 \times 45}=19 \mathrm{~J}
$$

After further calculations, we can get the input capacitance as:

$$
C_{\text {in }}=676 \mu F
$$




\subsection{Resonant Inductor Design}

Resonant inductor design, in order to achieve the lagging leg of zero voltage switching, must satisfy the following formula:

$$
\frac{1}{2} L_{r} I^{2}=\frac{4}{3} C_{\text {MOS }} V_{\text {in }}^{2}
$$

Which, $\mathrm{L}_{\mathrm{r}}$ is the resonant inductor, I was the primary current when lagging switch off, $\mathrm{C}_{\mathrm{MOS}}$ is the MOSFET drain-source capacitance, Vin is a DC voltage rectified and filtered.

In the actual design, taking into account the lagging achieve zero-voltage switching when more than $1 / 3$ full, $V_{\text {in }}$ should take the maximum. while the load current is $1 \mathrm{~A}$, the filter inductor current $\mathrm{I}_{\mathrm{Lf}}$ critical continuous, that is, the amount of its pulsation $\Delta \mathrm{i}_{\mathrm{Lf}}$ is $2 \mathrm{~A}$. In The case of the $1 / 3$ load, the following formula:

$$
I=\frac{I_{0} / 3+\Delta i_{L f} / 2}{K}=\frac{10 / 3+2 / 2}{1}=4.44
$$

IXFX2780Q switch drain-source capacitance $\mathrm{C}_{\mathrm{MOS}}=750 \mathrm{pF}, \mathrm{V}_{\text {in (max) }}=618 \mathrm{~V}, \mathrm{~L}_{\mathrm{r}}=$ $39 \mu \mathrm{H}$.

The resonant inductor core selected Siemens G42 models pot core, take the gap $\delta=$ $2 \mathrm{~mm}$, then according to the formula:

$$
L=\frac{\mu_{0} N^{2} A_{e}}{\delta}
$$

Where: $\mu_{0}$ is the magnetic permeability, the size of $4 \pi \times 10^{-7} \mathrm{H} / \mathrm{cm} . A_{e}$ is the cross-sectional area of the magnetic core, the size of $388 \mathrm{~mm} 2$. The $\mu 0, \mathrm{~A}_{\mathrm{e}}$ and $\delta$ into the formula, we get: winding turns $\mathrm{N}=4$, with 6 wire wounding a diameter of $0.62 \mathrm{~mm}$.

\subsection{Main Transformer Design}

(1) Main transformer primary secondary ratio

When designing high-frequency transformer, primary secondary ratio should be as large as possible, and the transformer turns ratio should be selected based on the lowest input voltage $\mathrm{V}_{\text {in }}$. Assuming the secondary maximum duty cycle is 0.85 , the secondary voltage $\mathrm{V}_{\mathrm{S}(\mathrm{min})}$ value can be calculated.

$$
V_{S(\min )}=\frac{V_{0(\max )}+V_{D}+V_{L f}}{D_{\max }}=\frac{320+2.5+2.5}{0.85}=382 \mathrm{~V}
$$

where, $\mathrm{V}_{\mathrm{o}(\max )}$ is the maximum output voltage; $\mathrm{V}_{\mathrm{D}}$ is the output rectifier diode on-state voltage drop; $\mathrm{V}_{\mathrm{Lf}}$ is the $\mathrm{DC}$ voltage drop of the output filter inductor. Therefore, the transformer primary secondary ratio is:

$$
K=\frac{V_{i n(\min )}}{V_{s(\min )}}=\frac{396}{382}=1.04 \approx 1
$$

(2) Core material selection

High-frequency transformer transfers $34 \mathrm{KHz}$ high-frequency square wave voltage with frontier steep in converter. Siemens N27 series ferrite material is used in the transformer core. Taking into account the power source output was $2200 \mathrm{~W}$, based on the core size and 
power relations, PM74 core model may be employed. According to B $\sim \mathrm{H}$ temperature characteristic curve, maximum operating flux density $B_{M}$ is:

$$
B_{m}=\frac{1}{3} B_{s}=\frac{1}{3} \times 0.45=0.15(T)
$$

(3) Primary and secondary turns

After selecting the PM74 models core, the secondary side can be determined by the following formula:

$$
N_{s}=\frac{V_{s(\min ) \times} D_{\max }}{4 f_{s} A_{e} B_{m}}
$$

Where $A_{e}$ is the effective permeability cross-sectional area of the core. Check the manual shows, $\mathrm{A}_{\mathrm{e}}=790 \mathrm{~mm}^{2}, \mathrm{~V}_{\mathrm{s}(\min )}=\mathrm{V}_{\text {in (min) }} / \mathrm{K}=396 \mathrm{~V}$, it may be drawn $\mathrm{N}_{\mathrm{s}}=20$, using $\mathrm{N}_{\mathrm{s}}=21$. According to the ratio $\mathrm{K}=1$ and the transformer turns ratio should be maximum principle, take the primary turns $\mathrm{N}_{\mathrm{f}}=23$.

(4) the number of transformer winding wire diameter and shares

Winding wire diameter selection should be based on current RMS:

$$
I_{\mathrm{sec}}=I_{0} \sqrt{0.5}=10 \times \sqrt{0.5}=7.071 \mathrm{~A}
$$

the conductor skin effect should be considered in the selection of wire diameter. At $34 \mathrm{KHz}$ frequency, the penetration depth $\Delta=0.35 \mathrm{~mm}$, should use the winding diameter of less than $0.70 \mathrm{~mm}$ copper wire. If the current density takes $4 \mathrm{~A} / \mathrm{mm}^{2}$, the cross-sectional area of the wire is:

$$
S=\frac{7.071}{4}=1.768 \mathrm{~mm}^{2}
$$

check the manual, and choose the kinked 6 wires with $0.62 \mathrm{~mm}$ diameter and $0.3019 \mathrm{~mm}^{2}$ cross-sectional area to wound.

(5) Checking window area

Because $\mathrm{N}_{\mathrm{f}}=23$ turns, $\mathrm{N}_{\mathrm{s}}=21$ turns, $\mathrm{A}_{1}=6 \times 0.62=3.7 \mathrm{~mm}^{2}=\mathrm{A}_{2}$, can be estimated window area $S_{0} \geq 790 \mathrm{~mm}^{2}$ (core area). Duty factor $K_{m}$ calculated by the following formula:

$$
K_{m}=\frac{N_{f} \times A_{1}+N_{s} \times A_{2}}{S_{0}}=0.20
$$

This shows that the design of the transformer window area can accommodate all winding.

\subsection{The Output Inductor Design}

From the side view of the output filter, PWM DC / DC converter is actually similar to a full-bridge converter BUCK, but its operating frequency is twice the switching frequency. The output inductor can be calculated according to the formula.

$$
L_{f}=\frac{V_{0(\min )}}{2 \cdot\left(2 f_{s}\right) \cdot\left(10 \% I_{0(\max )}\right)}\left[1-\frac{V_{0(\min )}}{\frac{V_{i n(\max )}}{K}-V_{l f}-V_{D}}\right]
$$


When this power supply input voltage up to $618 \mathrm{~V}$, output voltage as low as $180 \mathrm{~V}$, set the sum of $\mathrm{V}_{\text {If }}$ and $\mathrm{V}_{\mathrm{D}}$ to $5 \mathrm{~V}$, then $\mathrm{L}_{\mathrm{f}}=920 \mu \mathrm{F}$.

\subsection{Output Filter Capacitor Selection}

According to the manufacturers request, the ripple factor should be less than $0.2 \%$. because the electric power rated output voltage is $220 \mathrm{~V}$, the output ripple voltage deputy is less than $0.44 \mathrm{~V}$. Considering the diode turn-on and turn-off voltage spikes caused by power switch and output rectifier and DC bus voltage residual ripple, can make the output voltage of the AC ripple to be:

$$
\Delta V_{\text {OUT }}=100 \mathrm{mV}
$$

And $\mathrm{I}_{0}=10 \mathrm{~A}$, the minimum output capacitance is calculated by the following formula:

$$
C=\frac{0.2 I_{0}}{8 f \cdot \Delta V_{\text {out }}}=74 \mu F
$$

where, $\mathrm{I}_{0}$ : output current; $\Delta \mathrm{V}_{\text {out }}$ : allowable output voltage ripple peak; f: operating frequency.

Thus calculated capacitance value is the minimum, taking into account the actual, select $560 \mu / 400 \mathrm{~V}$ output filter capacitor.

\subsection{MOSFET and Output Rectifier Diode Selection}

Typically, the power transistor and the rectifying diode selection depends on its voltage stress and current stress. Since maximum of the DC voltage rectified and filtered is $618 \mathrm{~V}$, and the maximum value of the transformer primary current $\mathrm{I}_{\mathrm{p}}$ is $12 \mathrm{~A}\left(\mathrm{I}_{\mathrm{p}}=12 \mathrm{~A} / \mathrm{K}=12 \mathrm{~A}\right)$, the MOSFET tubes use IXYS company's IXFX27N80Q power tubes, rated voltage of $800 \mathrm{~V}$, rated current of $27 \mathrm{~A}$.

Because the secondary of the transformer is a full bridge rectifier circuit, the rectifier can be calculated to withstand maximum reverse voltage $\left(\mathrm{V}_{\mathrm{VD}}=618 \mathrm{~V}\right)$ and maximum current flowing through the rectifier $\left(\mathrm{I}_{0 \mathrm{VDmax}} \geq 2_{\mathrm{I} 0 \max }=24 \mathrm{~A}\right)$. According to both, the diode use IXYS company's DSEI30 diode that can withstand maximum current of 26A (more than 2 times the rated output current), the maximum reverse voltage $1200 \mathrm{~V}$.

\section{Experimental Results and Analysis}

In order to investigate whether the selected parameters to achieve the design requirements, the waveform of the transformer primary and secondary voltage, current waveforms and secondary rectifier output voltage was collected by an oscilloscope, and the power temperature and efficiency was tested.

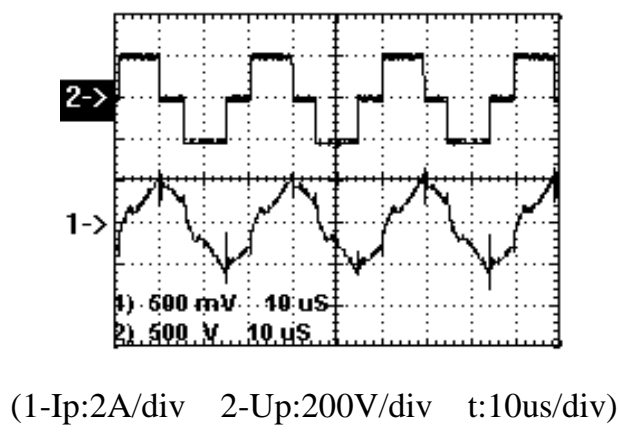

Figure 3. Current and Voltage Waveform of Primary 


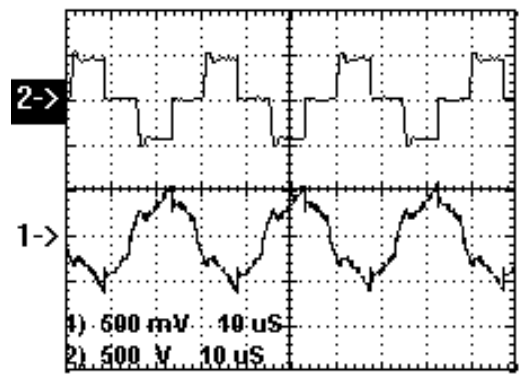

(1-Is: 2A/div 2-Us: 200V/div t:10us/div)

\section{Figure 4. Current and Voltage Waveform of Second}

Figure 3 shows the waveforms of transformer primary voltage and current when the input AC voltage is $380 \mathrm{~V}$ and the output is $220 \mathrm{~V} / 6.5 \mathrm{~A}$. As can be seen from the figure, the primary transformer voltage waveform is very clean. Primary current only when the current commutation, due to the transformer leakage inductance and current oscillations affect exists small spikes. Can also be seen from figure 3, the primary current slope during overshoot or undershoot is large, nearly equal to 1 , so that the current rises rapidly to the load current. This shows that the resonant inductor is almost at saturation point, resulting in a greatly duty cycle loss decreases.

Figure 4 shows the waveforms of transformer secondary voltage and current when the input AC voltage is $380 \mathrm{~V}$ and the output is $220 \mathrm{~V} / 6.5 \mathrm{~A}$. As can be seen from the figure, the secondary current waveform is very clean, and at the time of the commutation, spike smaller than the primary current. Can also be seen from the figure, there is little secondary voltage oscillation, which is caused by the leakage inductance of transformer secondary side and reverse recovery of the output rectifier.

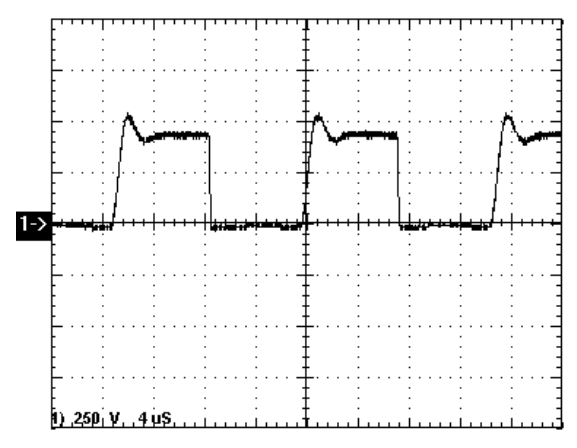

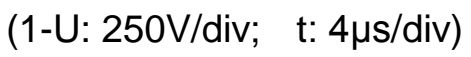

Figure 5. Output Voltage Waveform of Secondary

Figure 5 is the secondary circuit output voltage waveform. As can be seen from the figure, the output voltage of the secondary loop barely trailing edge spikes, indicating that the main transformer leakage inductance is small.

Table 1. Temperature Experiment of Main Components

\begin{tabular}{lllll}
\hline & $\begin{array}{l}\text { Secondary } \\
\text { Rectifier } \\
\text { Bridge }\end{array}$ & $\begin{array}{l}\text { MOSFET } \\
\text { Tube }\end{array}$ & $\begin{array}{l}\text { Resonant } \\
\text { Inductor }\end{array}$ & $\begin{array}{l}\text { Transfor } \\
\text { mer }\end{array}$ \\
\hline Air-condition & $51^{\circ} \mathrm{C}$ & $45^{\circ} \mathrm{C}$ & $64^{\circ} \mathrm{C}$ & $38^{\circ} \mathrm{C}$
\end{tabular}

Tabel1 shows the measured temperature of the main heating device after running twenty minutes when the ambient temperature is $28^{\circ} \mathrm{C}$, the power output is $220 \mathrm{~V} / 9.1 \mathrm{~A}$ and works under air condition. 
It can be seen easily when the main heating elements work at full load, the temperature is less than 75 , and meet the design requirements.

Table 2 shows that when the input and output voltages are constant $\left(\mathrm{U}_{\mathrm{i}}=380 \mathrm{~V}, \mathrm{U}_{0}=220 \mathrm{~V}\right)$, the power efficiency of different output current. As can be seen from the table, the overall efficiency of the power supply in the whole load range is up to more than $90 \%$.

Table 2. Supply Efficiency under Different Output Current

\begin{tabular}{|c|c|c|c|}
\hline $\begin{array}{c}\text { Input } \\
\text { Current(A) }\end{array}$ & Output & active & Efficiency $(\mathfrak{y} \%$ \\
\hline 1 & 220 & 196.9 & 89.5 \\
\hline 2 & 440 & 395.56 & 89.9 \\
\hline 3 & 660 & 595.32 & 90.2 \\
\hline 4 & 880 & 797.28 & 90.6 \\
\hline 5 & 1100 & 1004.52 & 91.32 \\
\hline 6 & 1320 & 1210.31 & 91.69 \\
\hline 7 & 1540 & 1404.48 & 91.2 \\
\hline 8 & 1760 & 1598.08 & 90.8 \\
\hline 9 & 1980 & 1787.94 & 90.3 \\
\hline 10 & 2200 & 1962.4 & 89.2 \\
\hline
\end{tabular}

\section{Conclusion}

According to the selected parameters, designed the power supply operation main circuit. The practical application shows better stability and reliability of the power supply, energy-saving effect, higher efficiency.

\section{Acknowledgment}

This work was supported by The Education Department of Hubei Province (Research on islanding detection of positive feedback voltage variable coefficient NO. D20121403) and Science and Technology Department of Hubei Province (Research on SOC estimation algorithm and equalizing charge of HEV lithium ion battery NO. 2010CDB05802).

\section{References}

[1] Y. Jang, "A new family of full-bridge ZVS converters", Applied Power Electronics Conference and Exposition, 2003, APEC '03, Eighteenth Annual IEEE, vol. 2, (2003), pp. 622-628.

[2] X. Yuan, "Pulse width Modulation DC / DC full-bridge Converter soft Switch Technology", Science Press, vol. 7, (1999).

[3] Q. Wang, "Practical electronic Transformer Materials and Devices Handbook", Liaoning Science and Technology Press, vol. 5, (2003).

[4] C.S. Leu, "Improved Forward Topologies for DC-DC Applications with Built-In Input Filter", Ph.D. Dissertation, Department of Electrical Engineering, Blacksburg, Virginia, 24 January, (2006).

[5] C. Zhao, S. D. Round and J. W. Kolar, "Full-Order Aver- aging Modeling of Zero-Voltage Switching Phase-Shift Bidirectional DC-DC Converters", Power Electronics, vol. 3, no. 3, 2010, pp. 400-410. 
[6] H.A. Shahab, Moghaddam, A. Ayatollahi and A. Rahmati, "Modeling and Current Programmed Control of a Bidirectional Full Bridge DC-DC Converter", Energy and Power Engineering, vol. 4, (2012), pp. 107-116.

[7] T. Mishima, E. Hiraki, T. Tanaka and M. Nakaoka, "A New Soft-Switched Bidirectional DC-DC Converter Topology for Automotive High Voltage DC Bus Architectures", IEEE Vehicle Power and Propulsion Conference, Windsor, 6-8 September, (2006), pp. 1-6.

[8] S. Padmanabhan, Y. Sukhi and Y. Jeyashree, "Quasi-Square Wave Mode Phase-Shifted PWM LCC Resonant Converter for Regulated Power Supply", Energy and Power Engineering, no. 1, (2009), pp. 201-210.

[9] N. Jain, K. P. Jain and J. Geza, "A zero voltage transition boost converter employing a soft switching auxiliary circuit with reduced conduction losses", IEEE Transactions on PE, vol. 9, no. 1, (2004), pp. $130-139$.

[10] J. M. Zhang, X.G. Xie, X.K. Wu, G.L. Wu and Z.M. Qian, "A novel zero-current-transition full bridge DC/DC converter”, IEEE Transactions on Power Electronics, Vol. 21, No. 2, (2006), pp. 354-361.

[11] W. Chen, X.B. Ruan and R.R. Zhang, "A novel zero-voltage-switching PWM full bridge converter", IEEE Transactions on Power Electronics, vol. 23, no. 2, (2008), pp. 793-802.

[12] C. Zhao, X.K. Wu, P.P. Meng and Z. M. Qian, "Optimum design consideration and implementation of a novel synchronous rectified soft-switched phase-shift full- bridge converter for low-output-voltage high-output- current applications", IEEE Transactions on Power Electronics, vol. 24, no. 2, (2009), pp. 388-398.

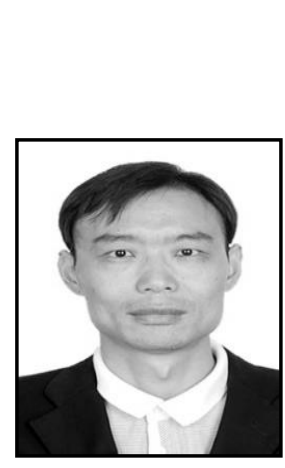

\author{
Author \\ Baowen Sun, 6/29/1975, China. Current position, grades: \\ Depart. of Mechanical and electrical Engineering, Guangdong \\ Institute of Science and Technology, Zhuhai, Guangdong, P. R. \\ China \\ University studies: Guangdong Institute of Science and \\ Technology \\ Scientific interest: Power conversion \\ Publications <number or main>: \\ Experience: From July 2004 to the present, engage in power \\ conversion technology research and teaching at Guangdong \\ Institute of Science and Technology.
}

